\title{
A reverse engineered pitch on Cremers et al. (2015), "Aggregate jump and volatility risk in the cross-section of stock returns"
}

\author{
Qingxia (Jenny) Wang, \\ ${ }^{a}$ The University of Queensland, Australia
}

\begin{abstract}
This pitching research letter presents the reverse-engineering process and personal reflections on a reverse engineered pitch by utilizing the pitching research template developed by Faff $(2015,2017)$. The pitch template is a simple and useful tool for helping PhD students and other academic researchers to develop research ideas and enhance communication in the research process. In this letter, I describe the steps and insights during reverse-engineering an existing journal paper into the pitching research template. In summary, I find it is very helpful for me to clearly understand the pitched paper and generate my research idea through applying the pitching research temple.
\end{abstract}

Keywords: Pitching research; template; reverse-engineering; cross-section; stock returns; jump risk; volatility risk

JEL codes: C51, G12, G17

\section{Introduction}

This pitching research letter describes my experience of conducting a reverse engineered pitch based on the application of the pitching research template developed by Faff $(2015,2017)$. Faff (2015) initially designs the pitch template for $\mathrm{PhD}$ students and early career researchers to generate research ideas. With regard to my academic background, I am currently undertaking a $\mathrm{PhD}$ in Finance. When I participated in the course named "RBUS6914 Process of Research in Business" taught by Prof. Faff, I was preparing my $\mathrm{PhD}$ confirmation report. My $\mathrm{PhD}$ thesis

\footnotetext{
${ }^{1}$ Corresponding author: Qingxia (Jenny) Wang, Business School, The University of Queensland, St Lucia, Queensland, 4072, Australia; Email address: q.wang@business.uq.edu.au
} 
is paper-based; that is, my thesis is composed of three journal papers to be completed. At that time, I had no clear idea what I should do for my third paper. I am passionate about the topic related to jump risk, but I do not know the research gap in this area. Fortunately, our first assignment for the course is reverseengineering the most relevant empirical paper to our main research interest or potential thesis topic. The purpose of this assignment is to help students on how to better understand the existing papers and how to extract useful information as the input for personal research topic. This skill is necessary for students who have read a broad range of prior literature to understand what has been done and what has not been done, and finally identify the research gap. This pitching research letter would provide some hints and insights in exploring research topics through my experience in reverse-engineering a research paper.

The remainder of this pitching research letter is structured as follows. Section 2 describes the reverse-engineering process. Section 3 presents personal reflections about using the pitching research template, and Section 4 concludes.

\section{The reverse-engineering process}

Table 1 presents the completed 2-page reverse engineered pitch template. In total, there are eleven items to be filled in the pitch template. This pitch template is completed for my first assignment for the course of RBUS6914. As my research interest is in relation to jump risk, I select Cremers et al. (2015) as my reverse engineered pitch paper. Even though I have read this paper before I conduct this reverse engineered pitch, I find that it is not straightforward for me to fill the pitch template. I needed to re-read the paper a couple of more times until I clearly understand the paper. At the same time, it is not a linear approach to identify these items in the template, but an iterative process. To illustrate the pitching process, I describe it in a sequential manner following the pitch template of Faff (2015) and I also refer to other previously published pitching research letters (e.g., Unda, 2015; Rekker, 2016; Wallin \& Spry, 2016).

The first item in the pitch template is the "Working title". This should be the easiest item to be filled in the reverse-engineering pitch as the pitched paper has already its title. In my opinion, it is not complete to just fill the title of the paper. It is better for us to display a full APA citation of the pitched paper in the "Working title" field or in the footnote. I suggest presenting the APA citation in the footnote, especially when the citation is pretty long, to keep a neat "Working title" field. The purpose for including an APA citation is to provide some insights to other readers who are interested in our reverse engineered pitch.

The second item is the "Basic research question". This item is not always clear. Some papers explicitly state the research question, but others do not. In the latter 
case, the answer to the research question is sometimes described in the introduction or other sections, so we need to identify the research question from these sections. Otherwise, we must summarize the research question after we re-read until we clearly understand the paper. For me, I find the research question in the introduction section of the pitched paper.

The third item is the "Key papers". Usually, the key papers are very contemporary (e.g., no more than three years), written by leading researchers (e.g., famous professors) in the field and published in the top tier journals (or unpublished papers available on SSRN and authored by "gurus"). Actually, these are the three rules of thumb provided by Faff (2017). With regard to the number of the key papers, it is suggested that at least one key paper is identified, but we should limit it to three key papers. In my opinion, it is easier to fill this field in the reverse engineered pitch. We can find that the authors often mention these key papers several times following the words like "closely follow ..." or "in a spirit of ...". I use these words to identify the key papers in my pitched paper.

The fourth item is the "Motivation/Puzzle". As Faff (2015) states "the hardest thing about doing research is starting it", we should first know the purpose for which we start our research. Some papers (e.g., in social science) are motivated by real world phenomenon, whereas the motivations of other papers emanate from the existing literature. This is normally based on broadly reading prior literature to identify the missing piece (i.e., research gap). The authors usually present the motivation and/or purpose in the abstract or introduction sections. My pitched paper describes the purpose in the introduction section.

The fifth item is the "Idea". The idea is about how we go about the research project and take actions to solve the problem and get the answer to the research question. The "idea" item closely follows up the "motivation/puzzle" that usually describes the idea and aim of the research project. Some papers introduce their ideas in the introduction section, but other papers may not explicitly describe their ideas. In the latter case, we need identify them from the paper.

The sixth item is the "Data". We need specify the data sample period and what kind of market the data covers (e.g., international market or local market, equity market or debt market). At the same time, we need show the data sources in case others want to get the same data to replicate our work. For example, what are the databases used to extract the required data. The "data" item is usually described in a separate section in the paper.

The seventh item is the "Tool". The tool is very important in dealing with the data and idea as Faff (2017) states that "without adequate tools/techniques, data and ideas are useless". The tool can be the econometric model, software or regression 
approach used to extract useful information from data and get meaningful results. Some papers may employ more complicated econometric models and statistical techniques. Whether we can clearly understand these tools or not is dependent on our knowledge background and relevant research skills.

The eighth item is the "What's new". This item is in relation to the novelty of the empirical research. If there is no novelty, the research work has no contribution. Most papers specify their novelty on the idea, but particular papers may contribute to the tool or research design. Faff (2013) suggests using the "Mickey Mouse" diagram to assess the research novelty. The research novelty often lies in the triple intersection zone with " $X$ " mark (see the "Mickey Mouse" diagram in Figure 1), which may be explicitly described in the abstract or introduction sections in the paper.

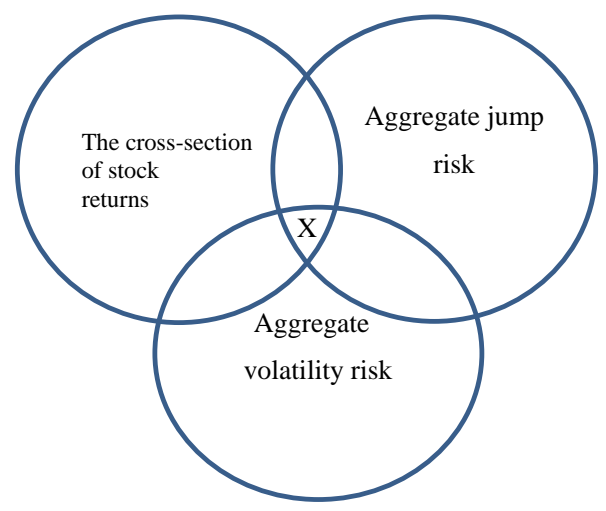

Figure 1. Mickey Mouse diagram characterizing novelty of research idea"

The ninth item is the "So what". It is relating to the significance of the research project. We need to answer the question "why is it important?" That is, how the outcome of the research project will impact people's behaviour or decisions. In most cases, the paper presents the importance of the research in the introduction and/or conclusion sections. However, in some cases, the paper does not mention about it, so we need to infer the research importance from the relevant parts of the paper.

The tenth item is the "Contribution". This is the bottom line of the research project. It brings together all of the previous items in the pitch template. The contribution item can be easily filled out as almost all papers describe the contributions in the introduction or conclusion sections. Otherwise, we need identify the contribution through our good understanding of the paper. 
The last item is the "Findings". In the real pitch, this item is the "other considerations", which discusses about collaborations, target journal and risk assessment. In the reverse engineered pitch, we need present three key findings. These findings can be about the support/refutation to existing theories or empirical results, impacts or implications for practical strategies. We usually find them in the result or conclusion sections.

\section{Personal reflections of using the pitching research template}

Prior to using the pitching research template, I use the EndNote to record the key points when I read existing literature. As a result, I have a lot of highlights and notes in the paper, and later I find that this practice is not an effective approach. When I write the literature review for my paper, I need to re-read the literature as I forget why I highlight that part and the notes are not recorded with purpose.

However, it is not an easy task for me to conduct the first reverse engineered pitch. I am confused about several items in the template. For example, what is the difference between the 'so what' and 'contribution'? As the pitched paper does not explicitly mention about these aspects, I need to read more times to extract relevant information and understand the meanings behind the information. After I finished the first reverse engineered pitch, I become more confident when I discuss my research project with my supervisors and other researchers.

The great benefit I would like to share is that I start to communicate with my supervisors more efficiently with the pitching research template. As we know, our supervisors are very busy, they work on several dimensions, including teaching, academic research, supervision and other administrative services. If we can summarize what we want to talk with them into 2-page well-structured papers, it will be very helpful to facilitate the discussion.

In summary, I find that the pitch template is a very useful tool to identify the main parts of a research project. It enables us to think systematically and craft our writing with purpose. Therefore, I strongly recommend this pitch practice to all $\mathrm{PhD}$ students regardless of the stage in their study and to other early career researchers who are facing the challenge to generate new research ideas.

\section{Conclusions}

This pitching research letter describes my experience in reverse-engineering an existing paper. It illustrates the reverse-engineering process and provides insights on how I benefit from this practice. Conducting a reverse engineered pitch is easier than to do a real pitch, because we can often find what we are looking for in the existing paper. However, the reverse engineered pitch could be a fundamental step 
for us to create a real research pitch. Sometimes we cannot identify the research gap from a voluminous literature. By the application of the pitching research template, the task becomes much easier to differentiate prior studies and identify what has not been done. However, the pitch process is not linear; it is an iterative process in which the work needs to be polished and improved to reach a satisfying result.

\section{Acknowledgments}

The author would like to thank Prof Robert Faff for teaching how to use the pitch template to generate research ideas in the course RBUS6914 Process of Research in Business delivered at the University of Queensland.

\section{References}

Bates, D. S. (2008) "The market for crash risk", Journal of Economic Dynamics and Control, vol. 32, no. 7: 2291-2321

Cremers, M., Halling, M. \& Weinbaum, D. (2015) "Aggregate jump and volatility risk in the cross-section of stock returns", The Journal of Finance, vol. 70, no. 2: $577-614$

Faff, R. (2013) "Mickey Mouse and the IDioT principle for assessing research contribution: discussion of 'Is the relationship between investment and conditional cash flow volatility ambiguous, asymmetric or both?", Accounting and Finance, vol. 53, no. 4: 949-960

Faff, R. (2015) "A simple template for pitching research", Accounting and Finance, vol. 55(2): 311-336

Faff, R. (2017) "Pitching research", available at SSRN: http://ssrn.com/ abstract $=2462059$

Rekker, (2016) "Converting planetary boundaries into action, a new approach to meeting global greenhouse gas targets: A pitch", Accounting and Management Information Systems, vol. 15: 160-167

Santa-Clara, P. \& Yan, S. (2010) "Crashes, volatility, and the equity premium: Lessons from S\&P 500 options", The Review of Economics and Statistics, vol. 92 , no. 2: 435-451

Unda, L. (2015) "Board of directors characteristics and credit union financial performance: a pitch", Accounting and Finance, vol. 55: 353-360

Wallin, A. \& Spry, A. (2016) "The role of corporate versus product brand dominance in brand portfolio overlap: A pitch", Accounting and Management Information Systems, vol. 15, no. 2: 434-439 
Table 1: Completed 2-page pitch template on jump risk

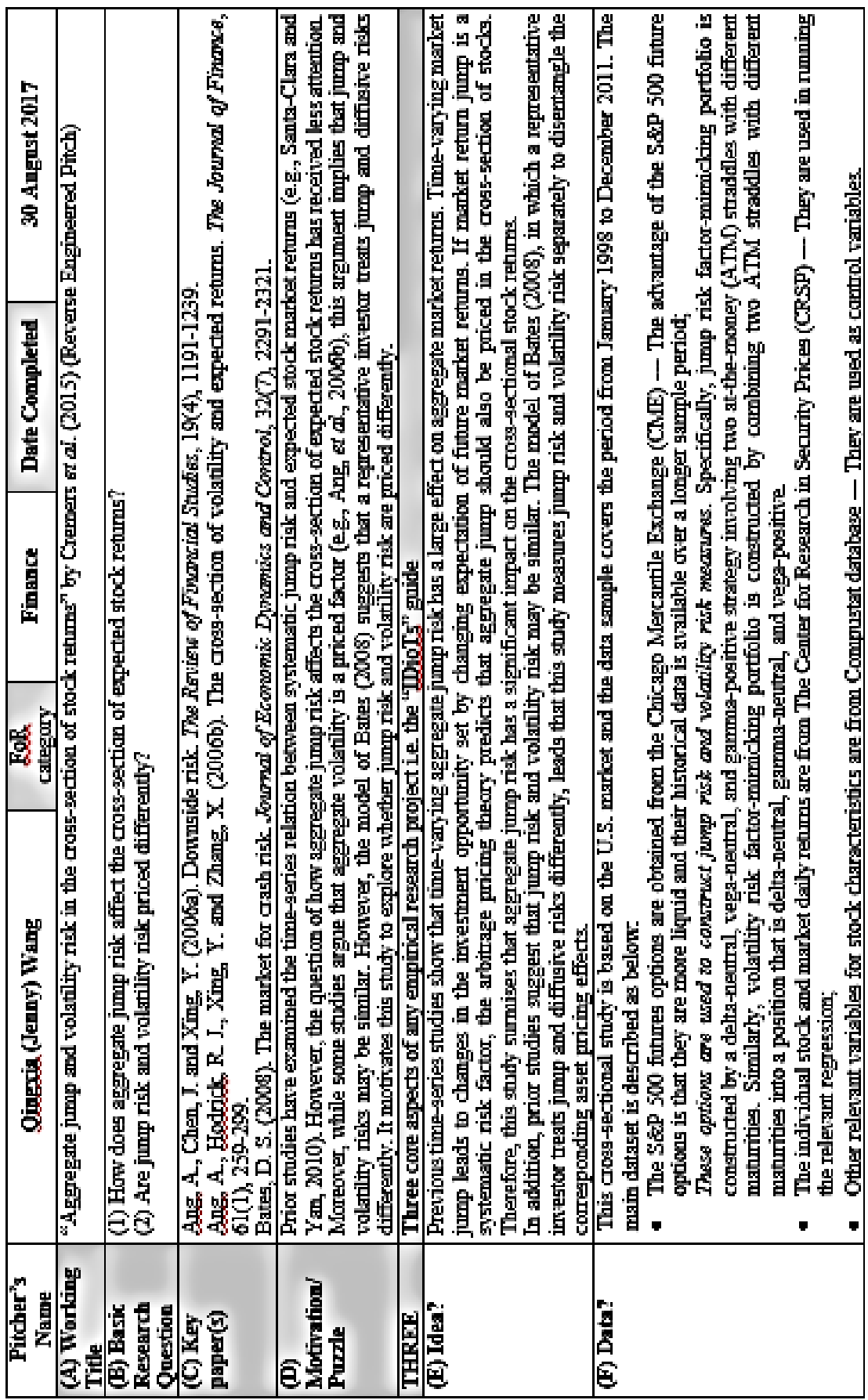




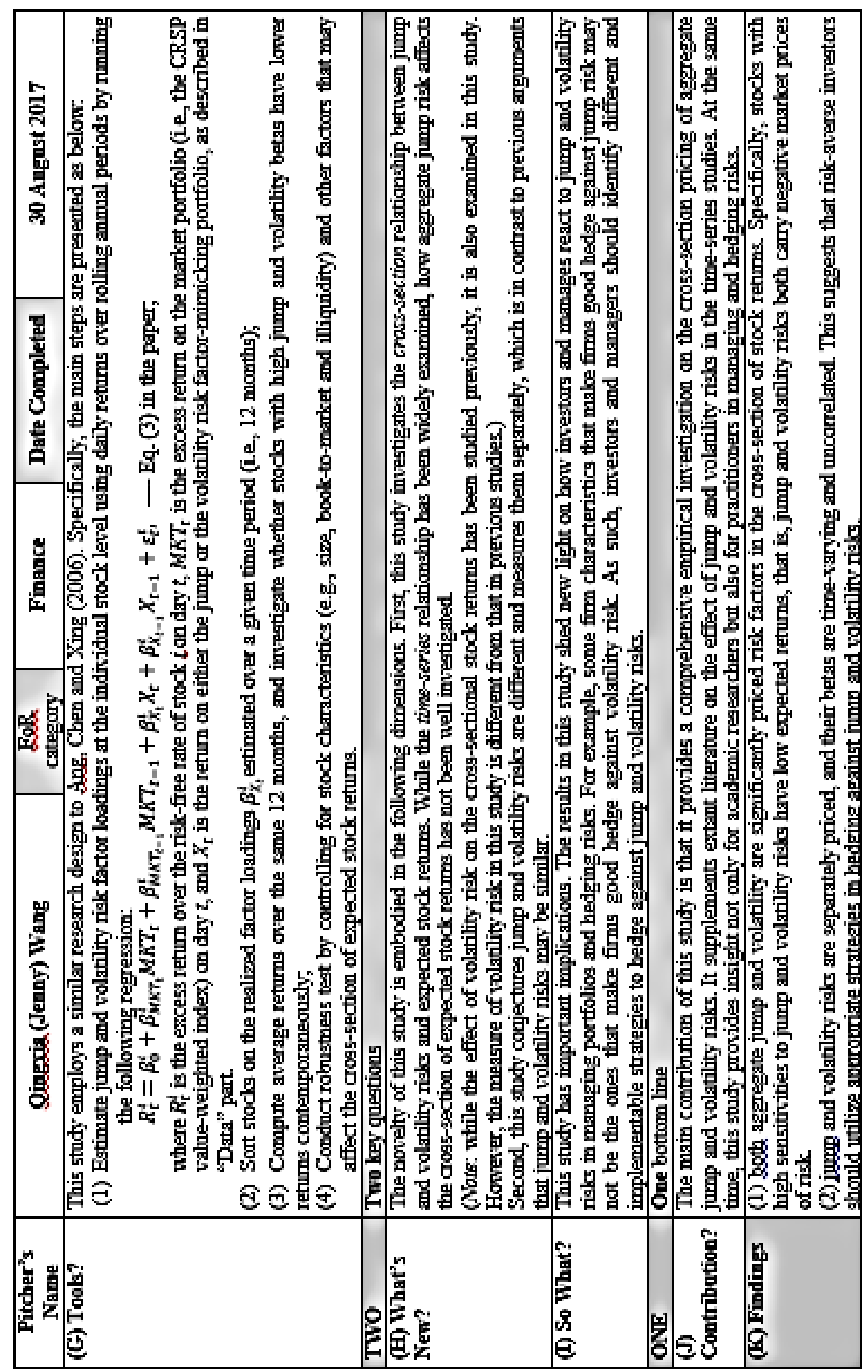

Vol. 17, No. 1 